\title{
The Factors Affecting the Occurrence of Renal Involvement in Children with IgA Vasculitis
}

\begin{tabular}{|c|c|c|}
\hline Author(s) & \multicolumn{2}{|c|}{ 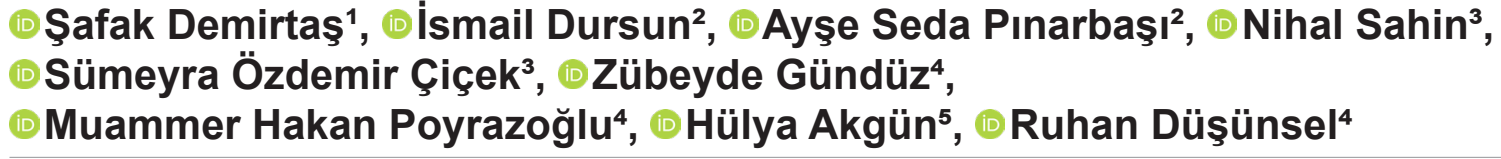 } \\
\hline Affiliation(s) & $\begin{array}{l}\text { 1Department of Pediatrics, Erciyes } \\
\text { }{ }^{2} \text { Department of Pediatric Nephrolog } \\
\text { 3Department of Pediatric Rheumato } \\
{ }^{4} \text { Department of Pediatric Nephrolog } \\
\text { } 5 \text { Department of Pathology, Erciyes }\end{array}$ & $\begin{array}{l}\text { Medicine, Kayseri, Turkey } \\
\text {, Faculty of Medicine, Kayseri, Turkey } \\
\text { sity, Faculty of Medicine, Kayseri, Turkey } \\
\text { ciyes University, Faculty of Medicine, Kayseri, Turkey } \\
\text { Medicine, Kayseri, Turkey }\end{array}$ \\
\hline $\begin{array}{c}\text { Article } \\
\text { Information }\end{array}$ & $\begin{array}{l}\text { Article Type: Original Articles } \\
\text { Article Group: Pediatric Nephrology }\end{array}$ & $\begin{array}{l}\text { Received: } 05.05 .2020 \\
\text { Accepted: } 01.09 .2020 \\
\text { Available Online: } 30.09 .2020\end{array}$ \\
\hline
\end{tabular}

Cite this article as: Demirtaş Ş, Dursun I, Pınarbaşı AS, Şahin N, Özdemir Çiçek S, Gündüz Z, Poyrazoğlu MH, Akgün H, Düşünsel R. The Factors Affecting the Occurrence of Renal Involvement in Children with IgA Vasculitis. J Pediatr Acad 2020; 1(2): 50-55.

\section{Abstract}

Henoch-Schönlein purpura or IgA vasculitis that involves small vessels is the most common vasculitis in childhood and the long term prognosis is contingent on the severity of renal involvement.In this study, we aimed to determine the frequency of organ involvements and to identify potential risk factors for renal involvement in children with IgA vasculitis. This study included 416 patients with IgA vasculitis who had been followed in our department between 1990 and 2016. The patients were retrospectively reviewed in terms of type of treatment, organ involvement and clinical outcome, and potential risk factors for renal involvement were determined. Overall, 416 patients with IgA vasculitis were identified, including 174 girls $(41.7 \%)$ and 242 boys (58.3\%). The mean age at presentation was $8.3 \pm 3.1$ years. The distribution of organ involvement was: skin involvement, $100 \%$; joint involvement, $77.1 \%$; gastrointestinal system (GIS) involvement, $58.6 \%$; renal involvement, $38.3 \%$; scalp edema, 10.1\%; scrotal involvement, 5.3\% (9.0\% in boys), central nervous system (CNS) involvement, 1.6\% and pulmonary involvement, $0.25 \%$. When risk factors for renal involvement were assessed, it was found that GIS involvement was more frequently seen in patients with nephritis $(p=0.01)$. Age, diastolic blood pressure and GIS involvement at the onset were found to be correlated with renal involvement. GIS involvement and diastolic blood pressure were found as risk factors for renal involvement. Age, elevation in diastolic blood pressure and GIS involvement were important findings in prediction of nephritis. In particular, patients with GIS involvement should be cautiously monitored for renal involvement.

Keywords: IgA vasculitis, Children, Kidney involvement

Correspondence: İsmail Dursun, Department of Pediatric Nephrology, Erciyes University, Faculty of Medicine, 38200, Talas, Kayseri, Turkey

E-mail: drdursun@hotmail.com 


\section{Introduction}

Immunoglobulin A (IgA) vasculitis, formerly known as Henoch-Schönlein purpura, is the most commonly encountered vasculitis in children, which is characterized by deposition of IgA within small vessels of skin, gastrointestinal system and kidneys. Common findings include palpable purpura without thrombocytopenia and accompanying arthritis-arthralgia, gastrointestinal involvement and renal involvement ranging from asymptomatichematuriatorapidly progressive glomerulonephritis. ${ }^{1}$ Although its etiology remains unclear, it has been reported that $\lg A$ vasculitis is more common following allergen exposure and upper respiratory tract infection caused by streptococci and other microorganisms. In addition, vaccines, drugs and insect bite may have facilitating role in the disease. Although lifethreatening pulmonary and CNS involvements can occur, renal involvement is primary organ involvement determining clinical outcomes. It can be seen in 17$58.1 \%$ of cases. $^{1-7}$ It generally develops within first 4-6 weeks after onset of $\lg A$ vasculitis.

Microscopic hematuria, proteinuria, hypertension, nephrotic syndrome, or acute or chronic renal failure may develop but end-stage renal disease is rare. ${ }^{1}$

The aim of this study was to review clinical and laboratory findings of patients who had been managed with a diagnosis of IgA vasculitis in our hospital, to identify other organ involvements predisposing renal disease, and to assess long-term outcomes in patients with nephritis.

\section{Materials and Methods}

We retrospectively reviewed files of patients who had been followed with a diagnosis of IgA vasculitis at Pediatric Nephrology and Rheumatology Department of Erciyes University, Medicine School between 1990 and 2016. This study was approved by The Ethics Committee of Erciyes University, Faculty of Medicine (approval date 02/12/2016, number 2016/627). Data regarding epidemiological characteristics (age, gender, history of allergy, insect bite or infection, family history and comorbid diseases), clinical and laboratory findings, organ involvement and treatments used were extracted from patient files. Overall, 416 patients were included into the study. The diagnosis of IgA vasculitis was made according to American College of Rheumatology criteria in patients presented before 2006 while it was made according to Pediatric Rheumatology European Society (PRES) criteria and EULAR/PRINTO/PRES consensus criteria in patients presented after 2006. ${ }^{8,9}$

Skin involvement was defined as presence of symmetrical purpura slightly arising from skin at extensor aspects of skin which doesn't blanch with pressure. Arthralgia was defined as pain alone in any joint while arthritis was defined

as presence of one or more findings of swelling, redness, warmth and limitation of movement in the joint regardless of pain. Gastrointestinal involvement was defined as severe, sharp, abdominal colic and/or presence of occult blood in stool, melena or hematochezia. ${ }^{10}$

Renal involvement was defined as presence of gross or microscopic hematuria regardless of proteinuria. Observation of $>5$ cells in centrifuged urine sample on microscope $(x 40)$ or $\geq 1+$ blood reaction in dipstick test

\section{Highlight}

A vasculitis is a multisystemic disorder that mainly affects skin, joints, gastrointestinal system (GIS) and kidneys. - In this study, pulmonary involvement was rare but had fatal course - Renal involvement was positively correlated with age, diastolic blood pressure and GIS involvement was considered as hematuria. Proteinuria was defined as presence of $\geq 1+$ reaction in dipstick test in case of normal urinary density or $>4 \mathrm{mg} /$ $\mathrm{m}^{2}$ protein and $>0.2 \mathrm{mg} /$ mg protein: creatinine ratio in 24-hours urine test. ${ }^{11}$ Pulmonary involvement was considered in case of pulmonary hemorrhage or interstitial pneumonia that couldn't explained otherwise. The CNS involvement was considered in case of severe headache, seizure, intracranial hemorrhage and encephalopathy that couldn't be explained otherwise. ${ }^{12}$

Anthropometric measurements, blood pressure values, detailed medical history and physical examination findings, urinalysis results, complete blood count values, biochemical parameters (urine and serum), immunoglobulin levels, acute phase reactant levels and complement levels at presentation were recorded. For assessment of proteinuria, protein: creatinine ratio in spot urine and/or 24-hours urine collection was calculated in all patients. Hypertension was defined as systolic or diastolic blood pressure values above 95 percentile according to age, gender and height. ${ }^{13}$ After assessment for organ involvement, patients with nephritis were evaluated in a more detailed manner.

The patients with kidney involvement were stratified into 5 categories based on modified Meadow criteria ${ }^{14}$ as follows: grade 1, microscopic hematuria; grade 2, persistent proteinuria and/or hematuria; grade 3, nephritic syndrome (hematuria, decrease in glomerular filtration rate, GFR, oliguria, hypertension, and edema); grade 4, nephrotic syndrome (proteinuria $>40 \mathrm{mg} / \mathrm{m}^{2}$ per hour or total protein/creatinine ratio on a spot urine sample $>3$ $\mathrm{mg}$ protein/mg creatinine, hypoalbuminemia with serum albumin $<2.5 \mathrm{~g} / \mathrm{dl}$ and/or hyperlipidemia/edema), and grade 5, mixed nephritic-nephrotic syndrome.

Renal biopsy results were classified according to International Study of Kidney Disease in Children (ISKDC) parameters. ${ }^{15}$ The GFR was calculated according to Schwartz formula. ${ }^{16}$ The estimated GFR $<60 \mathrm{ml} / \mathrm{min} / 1.73 \mathrm{~m}^{2}$ was considered as reduction in creatinine clearance.

All given treatments, treatment response and duration of treatment were also recorded. The findings of urinalysis, proteinuria in 24 hour urine collection or protein to creatinine ratio in spot urine at the beginning 
of treatment and remission status by treatment were recorded. Remission was defined as complete resolution of clinical and laboratory findings and complete recovery of urinary findings by treatment in patients with nephritis. Partial remission was defined as persistence of abnormal physical examination findings despite resolution of laboratory and clinical presentation, persistence of hematuria and/or proteinuria with partial resolution and need for a second therapeutic modality. Unresponsiveness to treatment was defined as lack of resolution in clinical and laboratory findings despite treatment. ${ }^{17}$

Treatment, urinary findings and biochemical parameters at last follow-up visit were recorded. Prognosis was assessed at the most recent follow-up according to Meadow criteria ${ }^{14}$ as follows: state $A$, normal (normal blood pressure, no proteinuria or hematuria, normal serum creatinine level); state $\mathrm{B}$, minor urinary abnormality $(<20$ $\mathrm{mg} / \mathrm{m}^{2}$ per hour proteinuria regardless of microscopic or macroscopic hematuria); state $\mathrm{C}$, active renal disease ( $>20 \mathrm{mg} / \mathrm{m}^{2}$ per hour proteinuria and/or elevated serum creatinine level); state $D$, renal failure (GFR<60 ml/ $\min / 1.73 \mathrm{~m}^{2}$ ).

\section{Statistical analysis}

Data were analyzed by SPSS version 22.0. ShapiroWilk test was used to assess normal distribution. Data with normal distribution are expressed as mean \pm standard deviation while data with skewed distribution are expressed as median (min=max). Student's t test was used to compare data with normal distribution while Mann Whitney test was used to compare data with skewed distribution. Univariate logistic regression analysis was used to identify variables which might be associated to renal involvement. To identify risk factors for renal involvement, variables found to be significant in univariate logistic regression analysis was assessed as independent variables in binary logistic stepwise regression model by backward elimination where renal involvement was dependent variable. A p value $<0.05$ was considered as statistically significant.

\section{Results}

This study was conducted on 426 patients diagnosed as $\lg \mathrm{A}$ vasculitis (HSP) including 174 girls (40.8\%) and 222 boys $(59.2 \%)$. Mean age at presentation was $8.3 \pm 3.2$ years. There was history of infection before onset of rash in 189 cases $(44.4 .0 \%)$ while there was a history of insect bite before diagnosis in 13 patients $(3.1 \%)$. Established drug or food allergy was present in only 3 patients $(0.7 \%)$. Familial Mediterranean fever and congenital heart disease were determined in seven and four, respectively as a co-morbid disease.

All 426 cases had typical skin manifestations. Joint involvement in $75.1 \%$, GIS involvement in $57.7 \%$, renal involvement in $39.9 \%$, scalp edema in $10.6 \%$, and CNS involvement in $1.6 \%$ of patients were detected. There was one patient with life-threatening pulmonary involvement characterized by pulmonary hemorrhage despite intensive immunosuppressive therapy, plasmapheresis and renal replacement therapy.
Table 1 shows laboratory findings of patients with at presentation and the diagnosis of $\lg A$ nephritis.

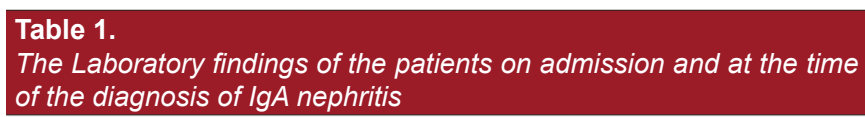
of the diagnosis of $\lg A$ nephritis

\begin{tabular}{lcc}
\hline Variables & On admission & $\begin{array}{c}\text { At the diagnosis of } \\
\text { IgA nephritis }\end{array}$ \\
\hline Hemoglobin $(\mathrm{g} / \mathrm{dL})^{*}$ & $12.4 \pm 1.5$ & $12.3 \pm 1.3$ \\
WBC $(/ \mu \mathrm{L})^{*}$ & $12060 \pm 5287$ & $12416 \pm 5392$ \\
Platelet $(/ \mu \mathrm{L})^{*}$ & $393587 \pm 136221$ & $380772 \pm 144124$ \\
BUN $(\mathrm{mg} / \mathrm{dl})^{*}$ & $14.3 \pm 11.2$ & $17.7 \pm 16.4$ \\
Creatine $(\mathrm{mg} / \mathrm{dL})^{\beta}$ & $0.5(0.15-5.6)$ & $0.6(0.2-5.6)$ \\
ESR $(\mathrm{mm} / \mathrm{h})^{*}$ & $34.8 \pm 25.7$ & $38.1 \pm 27.3$ \\
CRP $(\mathrm{mg} / \mathrm{L})^{\beta}$ & $16(2-287)$ & $2(2-182)$ \\
ASO $(\mathrm{IU} / \mathrm{mL})^{*}$ & $318 \pm 291$ & $320 \pm 290$ \\
C3* & $146.4 \pm 45.5$ & $142 \pm 42$ \\
C4 & $26.87 \pm 10.9$ & $28.7 \pm 24.5$ \\
IgA & $235.8 \pm 103.8$ & $245.9 \pm 117.9$ \\
\hline mean \pm standard deviation. ${ }^{*}$ median (minimum-maximum) \\
WBC: White blood cells; BUN: Blood urea nitrogen; ESR: Erythrocyte sedimentation rate; \\
CRP: C-reactive protein; ASO: Anti-streptolysin O; C3: Complement 3; C4: Complement 4; \\
IgA: Immunoglobulin A
\end{tabular}

Of 170 patients with renal involvement, there was microscopic hematuria in $94.3 \%$, proteinuria in $55.0 \%$ and gross hematuria in $51.8 \%$. The prevalence of dipstick proteinuria $\geq(2+), \geq(3+)$ and $\geq(4+)$ was $46.6 \%, 44.3 \%$ and $9 \%$, respectively. It was found that median microprotein: creatinine ratio was $1.2 \mathrm{mg} / \mathrm{mg}(0.17-10.9)$ while median 24 hour protein excretion was $27 \mathrm{mg} / \mathrm{m}^{2} /$ hour (0.4-510). Since baseline serum creatinine values were unavailable in 5 patients, 154 patients (67 girls and 87 boys) were included to final analysis of renal involvement in $\lg A$ vasculitis. Median time from diagnosis of $\lg A$ vasculitis to renal involvement was 1.5 weeks (0-68). There was no significant difference in renal involvement between boys and girls ( $p>0.05)$. Mean age was $9.1 \pm 3.2$ years in patients with nephritis whereas 7.8 years \pm 2.9 years in those without nephritis, indicating no significant difference $(p>0.05)$. Mean systolic and diastolic blood pressures were $107.4 \pm 16.1$ and $68.4 \pm 12.7 \mathrm{mmHg}$, respectively. Mean GFR was found to be $127.6 \pm 50.2$ $\mathrm{mg} / \mathrm{min} / 1.73 \mathrm{~m}^{2}$. Creatinine clearance was found to be decreased in 8 patients $(5.2 \%)$. According to modified Meadow scoring at presentation, there was grade 1 disease in 35 , grade 2 disease in 45 , grade 3 disease in 38 and grade 5 disease in 35 patients. There was no patient with grade 4 disease (Table 2).

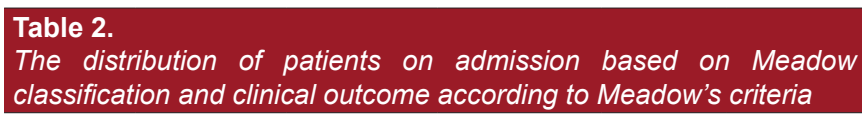

\begin{tabular}{lccccc}
\hline & State A & State B & State C & State D & Total \\
\hline Grade 1 & 26 & 7 & 2 & 0 & 35 \\
Grade 2 & 32 & 12 & 1 & 0 & 45 \\
Grade 3 & 25 & 10 & 3 & 0 & 38 \\
Grade 4 & 0 & 0 & 0 & 0 & 0 \\
Grade 5 & 19 & 10 & 6 & 1 & 36 \\
Total & 102 & 39 & 12 & 0 & 154 \\
\hline
\end{tabular}

Grade 1: Microscopic hematuria; Grade 2: Persistent mild proteinuria $\left(<20 \mathrm{mg} / \mathrm{m}^{2} / \mathrm{h}\right)$ and or hematuria; Grade 3: Nephritic syndrome (hematuria, low GFR, oliguria, hypertension, edema); Grade 4: Nephrotic syndrome [ proteinüri $\left(>40 \mathrm{mg} / \mathrm{m}^{2} / \mathrm{h}\right)$, hypoalbuminemia, hyperlipidemia and edema); Grade 5: Mix (nephrotic-nephritic syndrome). Meadow's criteria: $\boldsymbol{A}$, normal (no hypertension, urinary abnormality and protein excretion and normal plasma creatinine concentration); $\boldsymbol{B}$, minor urinary abnormalities (proteinuria $<20 \mathrm{mg} / \mathrm{m} 2 / \mathrm{h}$ with or without microscopic-recurrent macroscopic hematuria); $\boldsymbol{C}$, active renal disease (proteinuria $>20 \mathrm{mg} / \mathrm{m} 2 / \mathrm{h}$ and or elevated plasma creatinine level); $\boldsymbol{D}$, renal insufficiency (GFR below $60 \mathrm{ml} / \mathrm{min} / 1.73 \mathrm{~m}^{2}$ ) 
It was found that GIS involvement was more common in patients with nephritis than those without nephritis $(68.6 \%$ vs. $53 \%, p=0.01)$. No significant difference was detected regarding organ involvement other than GIS between patients with nephritis and those without nephritis. Joint involvement in 115, GIS involvement in 105, scalp edema in 10, scrotal involvement in 7 and CNS involvement in 4 of patients with nephritis were present.

Kidney biopsy was performed in 68 patients and histopathological findings were compatible with stage 1 in 21, stage 2 in 22, stage 3 in 23, stage 4 in 2 and stage 5 in 1 of patients. No patient had stage 6 histopathological changes. Of the patients with nephritis, oral prednisolone therapy was given to 120 patients whereas pulse methyl prednisolone therapy to 62 patients, cyclophosphamide to 5 , cyclosporine to 2 and ACE inhibitor to 46 patients. Eculuzimab was given in a child who had a genetic defect on the alternative pathway of complement system. At the end of 3 months of eculuzimab treatment, serum creatinine reduced and proteinuria decreased although we put her eculizumab her repeated kidney biopsy showed sclerosis in 17 of 26 glomeruli and cellular crescent in the rest of the glomeruli. She reached at end-stage renal disease (ESRD).

At last follow-up visit, mean age was $11.7 \pm 4.3$ years. Median protein to creatinine ratio in spot urine and protein excretion in $24 \mathrm{~h}$ urine collection were $0.18 \mathrm{mg} / \mathrm{mg}(0.05-$ 12.4) and $4.8 \mathrm{mg} / \mathrm{m}^{2} /$ per hour, respectively. Mean serum creatinine level was $0.59 \pm 0.16 \mathrm{mg} / \mathrm{dL}$. Based on Meadow classification at last control visit, there were 102 patients with state A disease, 39 patients with state $B$ disease, 12 patients with state $C$ disease and one patient with state $D$ disease (Table 2). As shown in Table 2, it was seen that findings of active disease was persisting at final control in 6 of 36 patients presented with manifestations of nephriticnephrotic syndrome while in $5.7 \% 35$ of patients presented with microscopic hematuria. In univariate analysis where renal involvement was dependent variable, a positive correlation was detected between renal involvement and age, diastolic blood pressure and GIS involvement (Table 3). In binary logistic regression model, these variables were found to be associated to risk for renal involvement. After adjustment according to age by using stepwise regression and backward elimination, it was found that each increase in diastolic blood pressure resulted in onefold increase while each increase in GIS involvement resulted in 1.8- folds increase in risk for renal involvement (Table 4).

\section{Table 3 .}

The univariate analysis between kidney involvement and other variables

\begin{tabular}{lccc}
\hline Variable & OR & $\mathbf{9 5 \%} \mathbf{C l}$ & $\mathbf{p}$ \\
\hline Age & 1.146 & $1.073-1.026$ & 0.001 \\
SBP & 1.013 & $0.999-1.026$ & 0.06 \\
DBP & 1.033 & $1.013-1.053$ & 0.001 \\
Gastrointestinal involvement & 1.737 & $1.152-2.621$ & 0.008 \\
Scalp edema & 0.539 & $0.263-1.107$ & 0.09 \\
Scrotal edema & 0.740 & $0.295-1.856$ & 0.5 \\
ESR & 1.008 & $0.999-1.016$ & 0.07 \\
\hline SBP: Systolic blood pressure; DBP: & Diastolic blood pressure; ESR; & Erythrocyte \\
sedimentation rate & & &
\end{tabular}

Table 4.

The factors affecting kidney involvement (Binary Logistic Regression)*

\begin{tabular}{lccc}
\hline Variable & OR & $\mathbf{9 5 \%} \mathbf{C l}$ & $\mathbf{p}$ \\
\hline DBP & 1.028 & $1.007-1.050$ & 0.010 \\
Gastrointestinal involvement & 1.807 & $1.105-2.956$ & 0.018 \\
\hline *Variables were adjusted for age; DBP: Diastolic blood pressure & \\
\hline
\end{tabular}

\section{Discussion}

In this study, we found that pulmonary involvement was rare but had fatal course. In addition, it was detected that renal involvement was more frequently seen in patients with GIS involvement; that renal involvement had positive correlation with age, diastolic blood pressure and GIS involvement; and that GIS involvement markedly increased risk for renal disease in patients with $\lg \mathrm{A}$ vasculitis.

$\lg \mathrm{A}$ vasculitis is slightly more common among boys with varying male: female ratios across the countries in the literature. ${ }^{18}$ For instance, in a study from Kuwait, male: female (M: F) ratio was reported as 0.72 in 102 patients. ${ }^{19}$ The $M$ : $F$ ratio was found to be 1.35 among 417 patients with $\lg \mathrm{A}$ vasculitis in a study from Spain ${ }^{20}$ while 1.23 among 121 patients in a study from South Korea conducted between 2004 and 2015. ${ }^{21}$ In Taiwan, the $\mathrm{M}$ : $\mathrm{F}$ ratio was reported to be 1.11 in a large series including 2759 patients with IgA vasculitis. ${ }^{22}$ In our study, the $\mathrm{M}$ : $\mathrm{F}$ ratio was found as 1.39 . This result is consistent with those reported by others. ${ }^{20-21}$

The distribution of organ involvements in $\lg A$ vasculitis varies depending on the definition criteria. Joint involvement has been reported in 50-80\% ${ }^{18,23,24}$ whereas GIS involvement in $50-75 \%$ of cases. ${ }^{25-27}$ Arthritis or arthralgia is not the first sign of disease in most cases; however, it may be observed as first sign in $15 \%$ of patients. ${ }^{28}$ Occasionally, abdominal pain that may be confused with acute abdomen followed by rash can occur. In a retrospective study from Turkey, GIS involvement was reported in $73 \%$ of 137 patients. ${ }^{29}$ In a study from Spain, GIS involvement was shown in $64.5 \%$ of 417 patients. ${ }^{20}$ In our study, the distribution of organ involvements was similar to literature. Intussusception was found in $4.5 \%$ of 243 patients with GIS involvement. The intussusceptions rate varies from $0.3 \%$ to $1.8 \%$ in patients with IgA vasculitis across the world. ${ }^{30,31}$ In a study on 214 patients from Turkey, GIS involvement it was reported as $1.4 \% .^{32}$ In our study, the frequency of intussusception was found to be higher than those reported in literature. This may be due to difference of experience between ultrasound operators, who can easily miss or detect small and important signs of intussusceptions. In our center, ultrasound is performed by radiologist.

The severity of renal involvement is one of the most important risk factors affecting long term prognosis in IgA vasculitis. ${ }^{1,18}$ In general, renal involvement occurs within 4-6 weeks after onset of disease. ${ }^{33,34}$ The incidence of renal involvement varies from study to study based on the definition criteria. In previous studies, it has been reported as $25-55 \%$. $^{1,17,28,34,35}$ In our study, median time from diagnosis of purpura to detection of nephritis was 
1.5 weeks and renal involvement was detected in 38\% of our patients. In our center, we do not perform kidney biopsy in children with minor urine abnormalities. So, 68 of patients with renal involvement underwent kidney biopsy. The distribution of patients based on histopathological findings may show variety between studies. Huang et al.$^{36}$ evaluated 245 patients with biopsy proven kidney involvement and found that $\% 90$ of patients had stage 2-3 changes based on ISKDC classification. The present study showed almost equal distribution between stage 1,2 and 3 . This finding may be due to the timing of kidney biopsy.

In clinical practice, the identification of early-stage nephritis is pivotal to prevent or delay chronic kidney disease. So, Knowing and guessing about the risk factors associated with renal involvement is crucial. ${ }^{37}$ Both the age of onset ${ }^{7,38,39}$ and severe abdominal pain were found as risk factors for nephritis. ${ }^{7,21}$

Mao et al. ${ }^{40}$ evaluated 535 with IgA vasculitis and found that age of onset $>6$ years, purpura on the upper limbs or face, and occult blood in stool were risk factors for development of nephritis. In a Finnish study on 223 patients, it was found that presence of severe abdominal pain was a risk factor for nephritis, causing 2.1 folds increase in risk for the development of nephritis. ${ }^{35}$ Recently, a meta-analysis has been published by Chan et al. ${ }^{37}$ They found that male gender; $>10 \mathrm{y}$ old; severe gastrointestinal symptoms (abdominal pain, gastrointestinal bleeding, and severe bowel angina); arthritis/arthralgia; persistent purpura or relapse; WBC>15×109/L; platelets>500×109/L; elevated ASO; and low C3 were associated with renal involvement in children with IgA vasculitis. In our study, GI involvement was found important risk factor for the development of nephritis with 1.8 fold increase in risk for nephritis by GI involvement (Table 4, $\mathrm{p}=0.01$ ). In addition, a positive correlation was detected between age of onset and renal involvement (Table 3). In a meta- analysis published by Mao et al. ${ }^{41}$ was shown that older age, elevated blood pressure, C3, hemoglobin, urea nitrogen, and hypoalbuminemia were risk factors for renal damage in patients with IgA vasculitis Authors did not mention the reason of the relationship between high blood pressure at baseline and the development of nephritis. The present study demonstrated baseline diastolic blood pressure is a risk factor for nephritis possibly through an unexplained mechanism. As known, hypertension is seen as part of acute HSP nephritis, with decreased GFR and fluid overload. ${ }^{1}$

Meadow scoring system is a useful tool to assess renal involvement at baseline and prognosis. ${ }^{14}$ In a study on 141 patients, Mir et al. ${ }^{17}$ evaluated 82 patients (58.1\%) with nephritis at baseline and follow-up visits by using modified Meadow criteria. Authors found that baseline findings had effect on prognosis. In that study, $94.5 \%$ of the patients with grade 1 and 2 disease according to modified Meadow criteria had better outcome than $62.0 \%$ of patients with grade $3-5$ disease in long term. In our study, active renal disease or end-stage kidney disease was apparent in patients with grade 5 disease characterized by nephritic-nephrotic syndrome at last follow-up ( $5 \%$ in grade $1-3$ vs. $19.4 \%$ in grade 5 ).
In Our cohort, there was a child who was nine years old girl presented with a typical clinical picture of HSPN verified with the kidney biopsy. Her complements levels were normal. She was given prednisolone, cyclosporine, azathioprine, cyclophosphamide, plasmapheresis, and Rituximab. However, she did not give the reasonable response to immunosuppressive medications. Repeated kidney biopsy showed sclerosis in 17 of 26 glomeruli and cellular crescent in the rest of the glomeruli. So, we decided to start Eculizumab for the rescue of renal function with an experience coming from IgA nephritis. ${ }^{42}$ Initially, she gave a partial response to Eculizumab. Unfortunately, we could not continue with Eculizumab regularly because of the difficulty to access it. Finally, she reached ESRD. A homozygous mutation in Factor $\mathrm{H}$ gene was detected in a study of a complement system. While she was on peritoneal dialysis, she experienced with osteomyelitis on the left foot. She died possibly because of a complication of osteomyelitis.

This study have some limitations including: 1) tissue specimens were obtained in only 68 patients due to failure in performing renal biopsy despite greater number of patients with renal involvement. Limited number of patients having kidney biopsy also restricts number of patients classified by ISKDC system and makes it difficult to establish clinic-pathological association and 2) lack of patients presented with isolated nephrotic syndrome resulted in failure to obtain data regarding prognosis of patients in this group.

\section{Conclusion}

IgA vasculitis is a multi-systemic disease. Gastrointestinal involvement is an important finding in prediction of renal involvement. Severity of baseline findings is an important parameter predicting prognosis of disease in patients with renal involvement. We think patients with $\mathrm{Gl}$ involvement should be closely monitored to detect renal involvement and prevent or delay chronic kidney disease.

Acknowledgements: This study was accepted as a poster at the 50th Anniversary Meeting of the ESPN, September 6-9 2017, SEC, Glasgow. The authors wish to thank Professor Nihal Hatipoglu for assistance statistics.

Ethics Committee Approval: The Ethical Committee of Erciyes University, Faculty of Medicine, approved this study (date: 02.12.2016, number: 2016/627).

Informed Consent: Written informed consent was obtained from patients who participated in this study.

Peer-review: Externally peer-reviewed.

Author Contributions: All of the authors declare that they have all participated in the design, execution, and analysis of the paper, and that they have approved the final version

Conflict of Interest: The authors have no conflict of interest to declare.

Financial Disclosure: The authors declared that this study has received no financial support. 


\section{References}

1. Paul B, Arvind B (2016) Leukocytoclastic Vasculitis: HenochSchönlein, In: Laxer RM, Lindsley CB, Wedderburn LR, Petty RE, eds. Textbook of pediatric rheumatology 7 th edition. Philadelphia: Elsevier, pp 452-61.

2. Tabel Y, Inanc FC, Dogan DG, Elmas AT. Clinical features of children with Henoch-Schonlein purpura: risk factors associated with renal involvement. Iran J Kidney Dis. 2012;6:269-274. [CrossRef]

3. Anil M, Aksu N, Kara OD, et al. Henoch-Schönlein purpura in children from western Turkey: a retrospective analysis of 430 cases. Turk J Pediatr. 2009;51:429-436. [CrossRef]

4. Cakar N, Ozçakar ZB, Soy D, et al. Renal involvement in childhood vasculitis. Nephron Clin Pract. 2008;108:c202-c206. [CrossRef]

5. Peru H, Soylemezoglu O, Bakkaloglu SA, et al. Henoch Schonlein purpura in childhood: clinical analysis of 254 cases over a 3-year period. Clin Rheumatol. 2008;27:1087-1092. [CrossRef]

6. Mir S, Yavascan O, Mutlubas F, Yeniay B, Sonmez F. Clinical outcome in children with Henoch-Schönlein nephritis. Pediatr Nephrol. 2007;22:64-70. [CrossRef]

7. Sano H, Izumida M, Shimizu H, Ogawa Y. Risk factors of renal involvement and significant proteinuria in Henoch-Schönlein purpura. Eur J Pediatr. 2002;161:196-201. [CrossRef]

8. Mills JA, Michel BA, Bloch DA, et al. The American College of Rheumatology 1990 criteria for the classification of HenochSchönlein purpura. Arthritis Rheum. 1990;33:1114-1121. [CrossRef]

9. Ozen S, Pistorio A, lusan SM, et al. EULAR/PRINTO/PRES criteria for Henoch-Schönlein purpura, childhood polyarteritis nodosa, childhood Wegener granulomatosis and childhood Takayasu arteritis: Ankara 2008. Part II: Final classification criteria. Ann Rheum Dis. 2010;69:798-806. [CrossRef]

10. Lau KK, Wyatt RJ, Moldoveanu Z, et al. Serum levels of galactose-deficient IgA in children with IgA nephropathy and Henoch-Schönlein purpura. Pediatr Nephrol. 2007;22:20672072. [CrossRef]

11. Siegel NJ, Van WSK, Devarajan P (2004) Pathogenesis of acute renal failure. In: Avner ED, Harmon WE, Niaudet P, eds. Pediatric Nephrology 5th ed. Philadelphia: Lippincott Williams\&Wilkins, pp 1225-51.

12. Gedalia A. Henoch-Schönlein purpura. Curr Rheumatol Rep. 2004;6:195-202. [CrossRef]

13. Tümer $N$, Yalçinkaya $F$, Ince $E$, et al. Blood pressure nomograms for children and adolescents in Turkey. Pediatr Nephrol. 1999;13:438-443. [CrossRef]

14. Meadow SR, Glasgow EF, White RH, Moncrieff MW, Cameron JS, Ogg CS. Schönlein-Henoch nephritis. Q J Med. 1972;41:241258. [CrossRef]

15. Yoshikawa N, White RH, Cameron AH. Prognostic significance of the glomerular changes in Henoch-Schoenlein nephritis. Clin Nephrol. 1981;16:223-229. [CrossRef]

16. Schwartz GJ, Feld LG, Langford DJ. A simple estimate of glomerular filtration rate in full-term infants during the first year of life. J Pediatr. 1984;104:849-854. [CrossRef]

17. Mir S, Yavascan O, Mutlubas F, Yeniay B, Sonmez F. Clinical outcome in children with Henoch-Schönlein nephritis. Pediatr Nephrol. 2007;22:64-70. [CrossRef]

18. Ardoin SP, Fels E (2016) Vasculitis Syndromes. In: Kliegman R, Stanton B, Geme J St, Schor N, eds. Nelson Textbook of Pediatrıcs, 20th ed. Philadelphia: Elsevier Saunders, pp 216-8.

19. Uppal SS, Hussain MA, Al-Raqum HA, et al. Henoch-Schönlein's purpura in adults versus children/adolescents: A comparative study. Clin Exp Rheumatol. 2006;24:S26-S30. [CrossRef]

20. Calvo-Río V, Loricera J, Mata C, et al. Henoch-Schönlein purpura in northern Spain: clinical spectrum of the disease in 417 patients from a single center. Medicine (Baltimore). 2014;93:106-113. [CrossRef]

21. Lee YH, Kim YB, Koo JW, Chung JY. Henoch-Schonlein Purpura in Children Hospitalized at a Tertiary Hospital during 20042015 in Korea: Epidemiology and Clinical Management. Pediatr Gastroenterol Hepatol Nutr. 2016;19:175-185. [CrossRef]
22. Yang $\mathrm{YH}$, Hung $\mathrm{CF}$, Hsu $\mathrm{CR}$, et al. A nationwide survey on epidemiological characteristics of childhood Henoch-Schönlein purpura in Taiwan. Rheumatology (Oxford). 2005;44:618-622. [CrossRef]

23. Lin $Q$, Min $Y, L i ~ Y$, et al. Henoch-Schönlein purpura with hypocomplementemia. Pediatr Nephrol. 2012;27:801-806. [CrossRef]

24. Novak J, Julian BA, Tomana M, Mestecky J. IgA glycosylation and IgA immune complexes in the pathogenesis of IgA nephropathy. Semin Nephrol. 2008;28:78-87. [CrossRef]

25. McCarthy HJ, Tizard EJ. Clinical practice: Diagnosis and management of Henoch-Schönlein purpura. Eur J Pediatr. 2010;169:643-650. [CrossRef]

26. Chen SY, Kong MS. Gastrointestinal manifestations and complications of Henoch-Schönlein purpura. Chang Gung Med J. 2004;27(3):175-181. [CrossRef]

27. Saulsbury FT. Henoch-Schönlein purpura in children. Report of 100 patients and review of the literature. Medicine (Baltimore). 1999;78:395-409. [CrossRef]

28. Dedeoğlu F, Susan Kim (2015). Henoch-Schönlein Purpura (immunglobulin A vasculitis): clinical manifestations and diagnosis. [Internet. Accessed December https://www.uptodate. com/contents/henoch-schonlein-purpura-immunoglobulin-avasculitis-clinical-manifestations-and-diagnosis.

29. Donmez O, Yıldııım NS, Durmaz O. Henoch Schnlein Purpuralı 137 Olgunun 10 Yıllık Retrospektif Değerlendirilmesi. J Curr Pediatr 2011;9:63-67. [CrossRef]

30. Harvey JG, Colditz PB. Henoch-Schönlein purpura--a surgical review. Aust Paediatr J 1984;201:13-6. [CrossRef]

31. Chang WL, Yang YH, Lin YT, Chiang BL. Gastrointestinal manifestations in Henoch-Schönlein purpura: a review of 261 patients. Acta Paediatr. 2004;93:1427-1431. [CrossRef]

32. Ece A, Yolbaş I, Balık $H$, et al. Henoch-Schönlein purpura in childhood: Review of 214 patients. J Clin Exp Invest 2012;3;9195. [CrossRef]

33. Trnka P. Henoch-Schönlein purpura in children. J Paediatr Child Health. 2013;4:995-1003. [CrossRef]

34. Chen JY, Mao JH. Henoch-Schönlein purpura nephritis in children: incidence, pathogenesis and management. World $\mathrm{J}$ Pediatr. 2015;11:29-34. [CrossRef]

35. Jauhola O, Ronkainen J, Koskimies O, et al. Renal manifestations of Henoch-Schonlein purpura in a 6-month prospective study of 223 children. Arch Dis Child. 2010;95:877-882. [CrossRef]

36. Huang YJ, Yang XQ, Zhai WS, et al. Clinicopathological features and prognosis of membranoproliferative-like Henoch-Schönlein purpura nephritis in children. World J Pediatr. 2015;11:338-345. [CrossRef]

37. Chan H, Tang YL, Lv XH, et al. Risk Factors Associated with Renal Involvement in Childhood Henoch-Schönlein Purpura: A Meta-Analysis. PLoS One. 2016;11:e0167346. [CrossRef]

38. Zhao YL, Liu ZJ, Bai XM, Wang YC, Li GH, Yan XY. Obesity increases the risk of renal involvement in children with HenochSchönlein purpura. Eur J Pediatr. 2015;174:1357-1363. [CrossRef]

39. Rostoker G. Schönlein-henoch purpura in children and adults: diagnosis, pathophysiology and management. BioDrugs. 2001;15:99-138. [CrossRef]

40. Mao Y, Yin L, Huang H, Zhou Z, Chen T, Zhou W. HenochSchönlein purpura in 535 Chinese children: clinical features and risk factors for renal involvement. J Int Med Res. 2014;42:10431049. [CrossRef]

41. Mao Song, Zhang Jianhua (2016) Risk factors for renal damage in Henoch- Schonlein purpura: a meta analysis. Int J Clin Exp Med 9:3607-13. [CrossRef]

42. Rosenblad T, Rebetz J, Johansson M, Békássy Z, Sartz L, Karpman D. Eculizumab treatment for rescue of renal function in IgA nephropathy. Pediatr Nephrol. 2014;29:2225-2228. [CrossRef] 